\title{
TIERED RISK ASSESSMENT OF CHEMICAL POLLUTION CAUSED BY MILITARY ACTIVITIES
}

\author{
Prof. Sergiy OREL \\ National Academy of the Ground Forces, Kiev, Ukraine \\ e-mail: orelsm0@gmail.com
}

\begin{abstract}
The methodology of environmental risk is becoming more common to assess the impact of chemical pollution on human beings and the environment, providing information for making environmental remediation decisions. This article examines the impact on human health chemicals that penetrated into river water as a result of an accident at a military ammunition depot. The river is the source of drinking water for the population. Assessing the impact of chemicals on the health of adults, adolescents and children is carried out in stages (tiers), from simple to complex. Assessment is carried out both for carcinogenic and non-carcinogenic substances. The first tier is executed by a deterministic methoda method in which all biological, chemical, physical, and environmental parameters are assumed to be constant and can be accurately specified. Deterministic methods commonly apply to either a "most likely" value for a parameter, or a conservative value. When the obtained values are insufficient for making the decision, the second tier of a risk assessment begins. The values in this case have the form of probability distributions that determine their variability. Processing the risk model with the help of the one-dimensional Monte Carlo method gives more accurate data in the form of risk distribution. However, the method does not consider the lack of knowledge about the values of input variables, so, at the third tier of a risk assessment, the two-dimensional Monte Carlo method is used. In this case, the specified values of risk look like trend charts and indicate the limits of probability of risk for a certain percentage of the population.
\end{abstract}

Key words: chemical pollution, tiered risk assessment, military activities, human health, drinkable water. 


\section{Introduction}

The work ${ }^{1}$ shows the typology of threats from chemicals that get into the environment. The cases of short-term exposure to the substance during fighting or emergency are mostly taken into account. It is assumed that the substances have a threshold effect, i.e. harmful effect is observed only at concentrations exceeding a certain level of matter. The level of concentration of the substance depends on the conditions of the human activity and is divided into maximum acceptable concentration (NDS) ${ }^{2}$, the maximum threshold concentration (NDSP) ${ }^{3}$ and maximum concentration in the short-term actions (NDSCh) ${ }^{4}$.

However, military activity leads to chemical pollution that affects human health for a long time, with a number of substances at low and ultra-low concentrations that do not carry toxic effects to man, but under certain conditions can cause cancer. According to modern views on carcinogenesis, the effect of carcinogens on human health has no threshold level of concentration.

Environmental risk assessment provides a basis for determining whether remediation or other risk management measures are warranted and to what extent. The costs of remediation or other risk management measures may ultimately be much lower using a risk-based approach compared to an approach based on comparison of contaminant concentrations to environmental quality guidelines.

1 J. Solarz Chemical contamination - typology of threats. NDU Scientific Quarterly no 4(93) 2013 p. 207-223.

2 NDS - weighted average of concentration for which the impact on the employee during the 8 - hour, daily and average weekly working time laid down in the Labour Code, by the period of its activity should not cause negative changes in his condition and the state of health of future generations.

3 NDSP - is concentration value, which due to the health hazard, the worker may not exceed in the work environment in no time.

$4 \mathrm{NDSCh}$ - is the average concentration that should not cause negative changes in the health of the worker, if present in the work environment no longer than 15 minutes and not more than 2 times during a shift in an interval of not less than one hour. 


\section{The essence of risk assessment}

Environmental risk analysis is an effective tool that integrates environmental data with management solutions ${ }^{5}$. Risk analysis consists of three phases: assessment, management and risk communication, where the risk assessment phase is the most important phase and consists of the following components:

1) identification of hazards - recording of all chemicals that pollute the environment to determine their toxicity to human beings and ecosystems;

2) evaluation of exposure - in general, purpose of exposure assessment is to characterise the mechanisms by which receptors are exposed to chemicals, and to quantify or categorise the magnitude of those exposures. This is also the assessment of received doses and the number of persons exposed to such and for which it seems to be probable;

3) evaluation of dependence "dose - response" - a search for numerical correlations that connect dose of substance with the prevalence of a particular adverse effect;

4) risk characterisation - includes evaluation of possible and real adverse effects to human health or the environment.

Risk assessment has some uncertainties that highlight the lack of knowledge at each stage of evaluation. The sources of uncertainties are:

1) during the identification of hazards - unidentified hazards, different results, quality and method of measurement in obtaining data, extrapolation of the results to the target population;

2) during the assessment of exposure - a conceptual model of contamination (a way of impact, distribution and transformation of pollutants in the environment, errors in determining and measuring the concentration of pollutants during field research), model of exposure (ways of getting contaminants into the body, determining the spatial and temporal boundaries), the determination of the target population;

5 Human and Ecological Risk Assessment: Theory and Practice Dennis J. Paustenbach (Ed.). - New York, NY: Wiley, 2002. - 1586 p.

6 EPA/540/1-89/002. Risk Assessment Guidance for Superfund: Human Health Evaluation Manual. Part A. Interim Final. Washington, DC, 1989. - http://www.epa.gov/ ower/riskassessment/ ragsa/index.htm. 
3) during the evaluation of dependence "dose - response" - errors in determining and measuring the concentration of pollutants in conducting epidemiological studies, interspecific and intraspecific differences in conducting toxicological studies, model of extrapolation from large to small doses of pollutants' impact on the body;

4) while characterising the risk, the uncertainty of earlier stages has its place.

In turn, the uncertainty can be divided into ignorance, i.e. the lack of knowledge about specific factors, parameters and models used in the analysis of risk, and variability, i.e. the inconstancy of parameters due to their natural heterogeneity ${ }^{7}$ If ignorance can be reduced by collecting additional data, increased measurement accuracy, improved models, etc., reducing the variability in this way is impossible.

In real life, risk assessment is often based on the use of deterministic, point data. Depending on the importance of the problem, the following cases are used:

- risk assessment based on average values of input variables;

- risk assessment based on the largest initial values of variables that should be expected in a certain place, usually 90 -th or 95 -th percentile.

Obviously, the last case is used for conservative estimates when it is important to avoid underestimating the danger. In this case, when the value of acceptable risk exceeds it, it is necessary to take measures for its reduction, and excessive conservatism may cause serious unjustified material costs. At the same time, using only an averaged meaning of the input values can lead to underestimation for certain, vulnerable populations or ecosystem components.

In order to improve the accuracy of estimates and to assess uncertainties, probabilistic risk assessment is used. Probabilistic estimation instead of point meaning of the input values uses their probabilistic distribution. Thus, probabilistic risk assessment provides unique and important additional information that is used for optimal risk management.

7 EPA 540-R-02-002. Risk Assessment Guidance for Superfund: Process for Conducting Probabilistic Risk Assessment. Vol. III. Part A. Washington, DC, 2001. - http://www.epa.gov/ superfund/RAGS3A/index.htm. 
To construct the probability distribution of risk, i.e. "promotion" of uncertainty from the beginning to the end of the model, different methods are used, but the most popular method is a numerical method of Monte Carlo. The process for a Monte Carlo simulation is illustrated in Fig. 1. Random variables $\left(\mathrm{V}_{1}, \mathrm{~V}_{2}, \ldots \mathrm{V}_{\mathrm{n}}\right)$ refer to exposure variables (e.g., body weight, exposure frequency, ingestion rage) that are characterised by probability distributions. A unique risk estimate is calculated for each set of random values. Repeatedly sampling $\left(\mathrm{V}_{\mathrm{i}}\right)$ results in a frequency distribution of risk $^{8}$. Comparing the value of acceptable risk with a given value from the distribution, you can define the area of unacceptable risk.

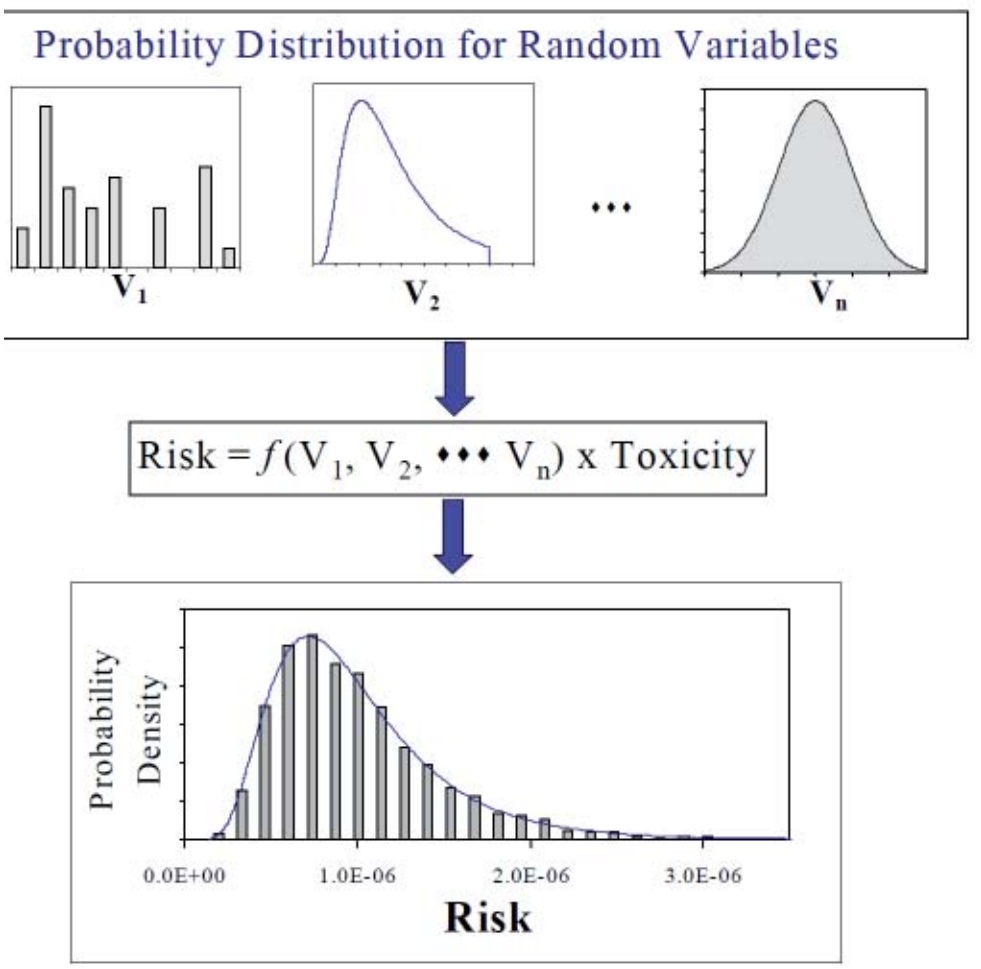

Source: EPA 540-R-02-002. Risk Assessment Guidance for Superfund: Process for Conducting Probabilistic Risk Assessment. Vol. III. Part A. http://www.epa.gov/superfund/RAGS3A/index.htm

\section{Figure 1. Conceptual model of Monte Carlo analysis}

8 EPA 540-R-02-002. Risk Assessment Guidance for Superfund: Process for Conducting Probabilistic Risk Assessment. Vol. III. Part A. http://www.epa.gov/superfund/RAGS3A/ index.htm. 
This method is called the one-dimensional Monte Carlo because it can be used to assess the impact of only a single component of uncertainty: variation or ignorance. Mixing these components in the probabilistic risk assessment using a one-dimensional Monte Carlo method is unacceptable.

For simultaneous evaluation variability and ignorance, the two-dimensional Monte Carlo method is used, the essence of which is clear from Fig. 2.

When implementing this method, a random value from distribution of the parameter that is determined by ignorance is firstly selected (external cycle). This value becomes "frozen" and inserted in distributions that are determined for the model, and an internal cycle similar to the one-dimensional method of Monte Carlo is implemented. After that, the new value is elected from the external cycle and the process repeats the required number of times.

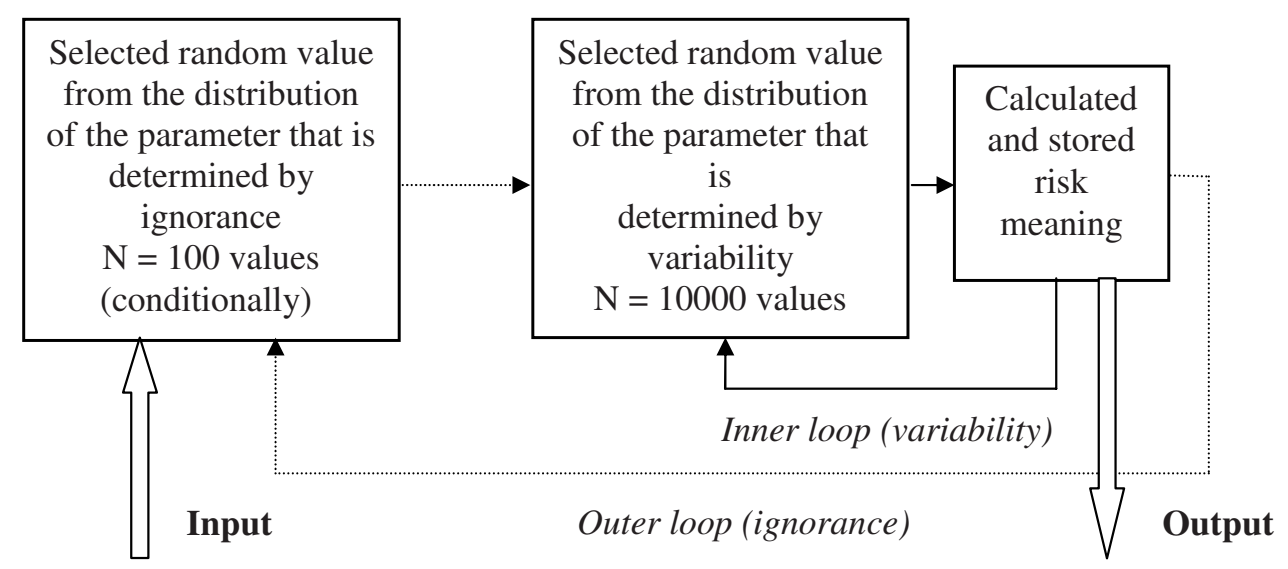

Source: own development.

Figure 2. Two-dimensional Monte Carlo method

The value of the two-dimensional Monte Carlo method can be demonstrated by Fig. 3. An analysis of this figure can provide a quantitative measure of the confidence in the fraction of the population with a risk exceeding a particular level. For example, a conclusion based on this type of output might be: "...while the best estimate for the variability distribution for risk across the target population indicates that $10 \%$ of the individuals exposed under these circumstances have a risk exceeding permissible value in $1 \mathrm{E}-06$, the uncertainty is such that we can only be 
reasonably certain (e.g., 95\% confidence) that no more than $20 \%$ of the exposed population has a risk that exceeds 1E-06..." (vertical confidence interval).

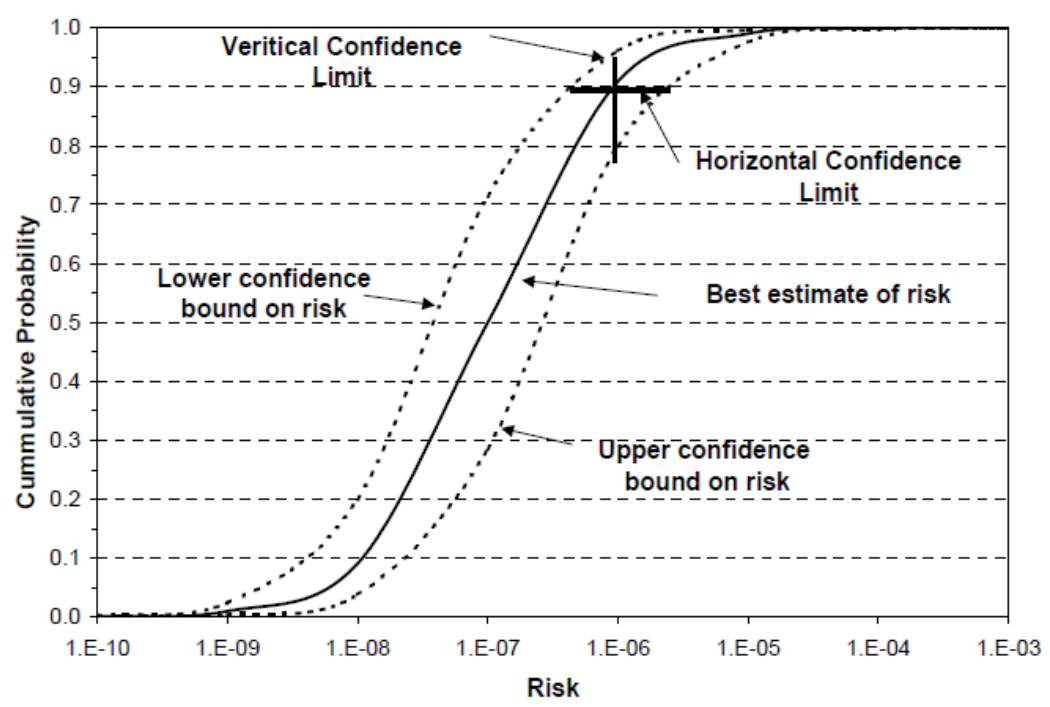

Source: EPA 540-R-02-002. Risk Assessment Guidance for Superfund: Process for Conducting Probabilistic Risk Assessment. Vol. III. Part A. http://www.epa.gov/superfund/RAGS3A/index.htm.

Figure 3. Illustration of risk assessment while implementing the two-dimensional Monte Carlo method

Additionally, the output from a two-dimensional Monte Carlo assessment can provide a quantitative measure of the confidence in the risk estimate for a particular fraction of the population. This type of output might support the following type of conclusion: “...while the best estimate for the variability distribution for risk across the target population indicates that $10 \%$ of the individuals exposed under these circumstances have a risk exceeding 1E-06, the ignorance is such that we can only be reasonably certain (e.g., 95\% confidence) that the risk for this group of individuals does not exceed 2E-06..." (horizontal confidence interval) ${ }^{9}$.

It should be noted that the term "confidence interval" in this case is treated quite freely and does not necessarily correspond to the value that can be obtained in the

9 EPA 540-R-02-002. Risk Assessment Guidance for Superfund: Process for Conducting Probabilistic Risk Assessment. Vol. III. Part A. http://www.epa.gov/superfund/RAGS3A/ index.htm. 
case of statistical analysis of experimental data. The lengths of the horizontal and vertical limits of the confidence interval can be defined by any percentile of value distribution, which is determined by ignorance.

Using the two-dimensional Monte Carlo method, we can build similar distributions for all values of limits of confidence interval and build a trend diagram with reflection of confidence intervals for any percentile of risk distribution.

\section{Tiered risk assessment}

Although probabilistic risk assessment can provide useful information for its management, it is not always necessary to make complex calculations, and for probabilistic models it is not always necessary to implement uncertainty analysis. This is very often when the useful information that is enough for decision making can be obtained from deterministic point values. The level of difficulty of risk assessment must be appropriate to the task. A tiered approach to risk assessment from deterministic point estimates to probablistic is recommended by environmental protection agencies of different countries, including the USEPA (US Environmental Protection Agency). The main feature of the approach is the repeated re-evaluation of risk at each stage to determine the adequacy of information for making environmental protection decisions.

The scheme of tiered approach to risk assessment is shown in Fig. 4.

Tier 1. At the first stage, the comparison of determined risk value with the acceptable one is rather simple, because the determined value is the number that exceeds or does not exceed the acceptable one. The variability of the computational model can be estimated using average values or their upper 95\% confidence limits. Ignorance is estimated by using different confidence boundaries of certain point values.

Calculations on the risk model equations using different values of input variables, such as average values, and the values of the upper 95\% confidence limits or maximum values give the average risk value, risk of reasonable maximum exposure, and maximum possible exposure. Depending on the research tasks, 
risk assessment can lead to these next results: 1 ) information sufficient for making environmental protection decisions; 2 ) information is insufficient.
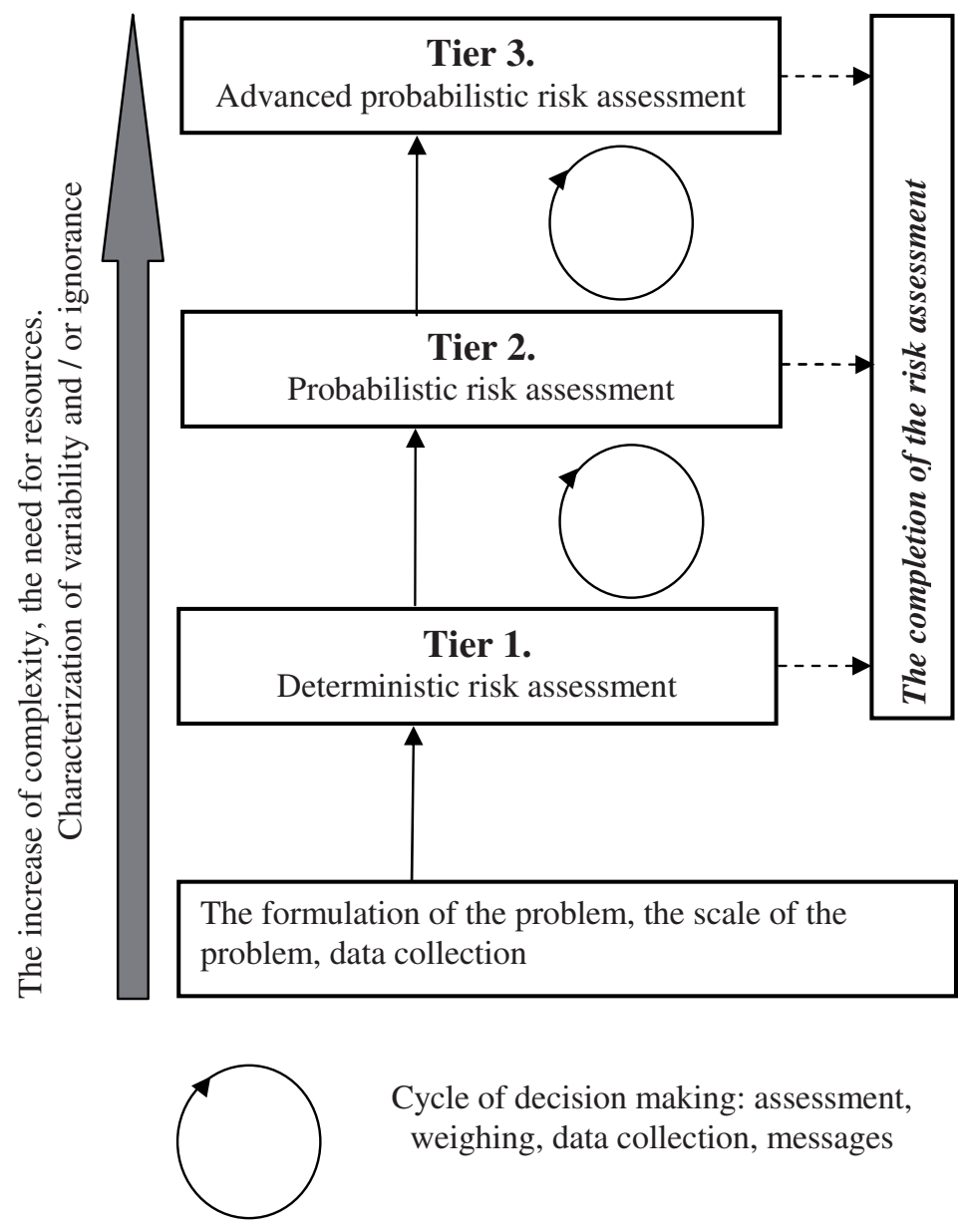

Cycle of decision making: assessment, weighing, data collection, messages

$-\ldots \quad$ Risk assessment can be completed at every stage

Source: EPA 540-R-02-002. Risk Assessment Guidance for Superfund: Process for Conducting Probabilistic Risk Assessment. Vol. III. Part A. http://www.epa.gov/superfund/RAGS3A/index.htm.

Figure 4. The scheme of the Tiered Approach to Risk Assessment

If the information is sufficient - risk manager quits the calculations and the risk assessment on the 1 tier (see Fig. 4). The decision may be the following: 1) there is no need for environmental protection; 2) there is a need for environmental protection. In the first case, the determined risk value does not exceed the 
permissible level, for example RISK $<10^{-6}$. In the second case, the level is much higher than normal, $R I S K>10^{-3}$.

The information is not enough for decision making when the risk value is between acceptable and unacceptable ( $R I S K=10^{-4}-10^{-6}$ ) and it is difficult to define it. In this case, risk manager must gather additional information, conduct consultations with experts and stakeholders and/or advance to the next tier to reduce uncertainty.

Tier 2. On the second tier, it is necessary to conduct an imitation test of the model in order to reduce uncertainty. The second tier is characterised by assessment of risk variability with the help of the one-dimensional Monte-Carlo method. If necessary, with the help of this method, it is also possible to estimate ignorance while determining fixed risk values, e.g. for average, reasonable maximum and maximum possible exposure, that is for 50, 90, 95, 99 percentile of risk distribution. So, on the second tier you can get the answers to the following questions: 1 ) whether the value of acceptable risk is withn the range of acceptable values risk; 2) what is the value of the confidence interval at a certain probability $(50,90,95$, 99)\% for the average level of risk? At the same time, it is necessary to avoid using together distributions of variability and ignorance for estimating risk distribution. It is possible to obtain several risk distributions, which reflect its variability with certain, fixed parameters that reflect its ignorance.

Similarly to the first tier, after completion of the second stage, there are two results: 1) information sufficient for making environmental decisions; 2) not enough information.

If the information is sufficient - manager ceases risk calculations and risk assessment completes the second tier (see Fig. 4). The decision can be as follows: 1) no need for environmental protection; 2) there is a necessity for environmental protection. There is no need for environmental protection when the range of the risk or a special value from the distribution of risk is well below the acceptable level. Accordingly, in the opposite case, there is a need for environmental protection.

Insufficient information for making decisions can be considered when:

1) the average risk value at reasonable maximum exposure (usually 95 percentile) almost equals the maximum value that is set by environmental authorities;

2) uncertainty in risk assessment depends not only on the variability of one or more parameters, but on the ignorance of some of them; 
3) results of the risk assessment determined in the first tier differ significantly from the probabilistic risk assessment.

In this case, it is necessary to move to the third stage of risk assessment. Again, it should be noted that transition to the next stage only makes sense when the cost of additional information does not exceed the cost of environmental protection. Therefore, the decision to move to a higher level should be consistent with the risk managers and stakeholders.

Stage 3. In the third stage, using the two-dimensional Monte Carlo method makes distributions of the risk with a reasonable level of uncertainty. This answers the question: does the required risk value fall within the acceptable range (for example a range that corresponds to reasonable maximum exposure) of the distribution of risk with a reasonable level of uncertainty. Typically, the answer to this question satisfies most requirements for researchers conducting the risk assessment.

The aim of this work is to display the importance and usefulness of tiered risk assessment in the event of environmental contamination caused by military activity.

\section{Research results}

The research is based on the following work ${ }^{10}$, which contains information about contamination of the environment after the accident at the ammunition depot in Novobohdanivka, Zaporozhye region, Ukraine that happened between 6 and 15 May 2004.

After the accident, the river Molochna, which was widely used by inhabitants of Troitske village as the only source of drinkable water, was contaminated by some chemicals that changed its composition (Table 1.).

10 S.I. Azarov, V.I. Palamarchuk, V.L. Sydorenko. Risk assessment for population, which uses drinking water after accident on an ammunition depot. Transactions of Kremenchuk Mykhailo Ostrohradskyi national university No 5 (64) pt.1 2010 p. 141-144 (in Ukrainian). 


\begin{tabular}{|l|l|l|l|l|l|l|l|l|}
\hline Parameter & $\mathrm{Cu}$ & $\mathrm{Mn}$ & $\mathrm{Zn}$ & $\mathrm{Cd}$ & $\mathrm{Pb}$ & $\mathrm{Cr}$ & $\mathrm{Ni}$ & $\mathrm{Fe}$ \\
\hline Ion concentration & $9,5 \pm$ & $0,414 \pm$ & $0,97 \pm$ & $0,021 \pm$ & $0,62 \pm$ & $0,239 \pm$ & $1,06 \pm$ & $11,6 \pm$ \\
in water, $\mathrm{mg} / \mathrm{l}$ & 0,9 & 0,004 & 0,1 & 0,001 & 0,4 & 0,002 & 0,06 & 0,3 \\
\hline
\end{tabular}

Table 1. Data on the presence of soluble forms of inorganic compounds in surface waters of the Molochna river

The paper did not present data on the composition of water before the accident, thus we cannot estimate the additional risk for drinkable water contaminated as a result of the accident; we can only estimate the overall risk from consumption of contaminated water.

\section{Tier 1. Deterministic risk assessment}

Carcinogenic risk is defined by the equation $R I S K=\sum_{i=1}^{N_{R}} I C R_{i}$,

where RISK - value of individual cancer risk, caused by the action of $N_{R}$ carcinogens;

$I C R$ - value of individual cancer risk, caused by the action of $i$ carcinogen;

$N_{R}$ - the total number of carcinogens in water.

$$
I C R=A D D \cdot S F
$$

where $A D D$ - daily dose of hazardous chemicals consumed by a human being; $S F$ - risk factor for the substance, which characterises the degree of augmentation of cancer risk with increasing doses per unit.

Non-carcinogenic hazard risk is determined by index $H I$

$$
H=\sum_{j=1}^{N} \boldsymbol{Q}_{j},
$$

where $H Q$ - hazard quotient of $j$ substance;

$N$ - the total amount of harmful substances in water. 


$$
H Q=A D D / R f D,
$$

where $R f D$ - reference dose, that is a numerical estimate of a daily oral exposure to the human population, including sensitive subgroups such as children, that is not likely to cause harmful effects during a lifetime.

The average daily dose of $A D D$ is determined from the equation

$$
A D D=(C w \cdot C R \cdot E F \cdot E D) /(B W \cdot A T)
$$

where $C w$ - concentration of harmful chemicals in drinking water ;

$C R$ - the average consumption of water per day;

$E F$ - frequency of exposure;

$E D$ - duration of exposure in days;

$B W$ - the average weight of the human body during exposure;

$A T$ - average exposure period in days.

Calculations were conducted separately for adults and children. Initial data is

\begin{tabular}{|c|c|c|c|c|c|c|c|c|}
\hline Parameter & $\mathrm{Cu}$ & $\mathrm{Mn}$ & $\mathrm{Zn}$ & $\mathrm{Cd}$ & $\mathrm{Pb}$ & $\mathrm{Cr}$ & $\mathrm{Ni}$ & $\mathrm{Fe}$ \\
\hline $\mathrm{Cw}, \mathrm{mg} / \mathrm{l}$ & 9,5 & 0,414 & 0,97 & 0,021 & 0,62 & 0,239 & 1,06 & 11,6 \\
\hline$R f D$ cron., $\mathrm{mg} / \mathrm{kg}$ & 0,019 & 0,14 & 0,3 & 0,0005 & 0,0035 & 0,005 & 0,02 & 0,3 \\
\hline$S F,(\mathrm{mg} /(\mathrm{kg} \cdot \text { day }))^{-1}$ & -- & $-\cdots$ & $-\cdots$ & 0,38 & 0,047 & 0,42 & 0,91 & --- \\
\hline$C R, \mathrm{l} /$ day & \multicolumn{4}{|c|}{ children -1} & \multicolumn{4}{|c|}{ adults - 2} \\
\hline$E F$, day & \multicolumn{4}{|c|}{ children -350} & \multicolumn{4}{|c|}{ adults -350} \\
\hline$E D$, day & \multicolumn{4}{|c|}{ children- 2190 (6 years) } & \multicolumn{4}{|c|}{ adults - 10950 (30 years) } \\
\hline$B W, \mathrm{~kg}$ & \multicolumn{4}{|c|}{ children - 15} & \multicolumn{4}{|c|}{ adults -70} \\
\hline$A T$, day & \multicolumn{4}{|c|}{$\begin{array}{l}\text { children - } 2190 \text { (6 years), } \\
\text { carcinogens - } 25550 \text { ( } 70 \text { years) }\end{array}$} & \multicolumn{4}{|c|}{$\begin{array}{l}\text { adults - } 10950 \text { ( } 30 \text { years), } \\
\text { carcinogens - } 25550 \text { ( } 70 \text { years) }\end{array}$} \\
\hline
\end{tabular}
presented in table 2, Table 3 shows the results of calculations.

Table 2. Input data for deterministic estimation of hazard quotients and carcinogenic risk from water from the Molochna river chemical contamination

\begin{tabular}{|l|l|l|l|l|l|l|l|l|l|}
\hline Parameter & $\mathrm{Cu}$ & $\mathrm{Mn}$ & $\mathrm{Zn}$ & $\mathrm{Cd}$ & $\mathrm{Pb}$ & $\mathrm{Cr}$ & $\mathrm{Ni}$ & $\mathrm{Fe}$ & $\Sigma$ \\
\hline$H Q$ (children) & 32,0 & 0,2 & 0,2 & 2,7 & 11,3 & 3,1 & 3,4 & 2,5 & $H I=55,3$ \\
\hline HQ (adults) & 13,7 & 0,1 & 0,1 & 1,2 & 4,9 & 1,3 & 1,5 & 1,1 & $H I=23,7$ \\
\hline ICR (children) & --- & --- & --- & $4,37 \mathrm{E}-05$ & $1,60 \mathrm{E}-04$ & $5,50 \mathrm{E}-04$ & $5,29 \mathrm{E}-03$ & --- & $R I S K=6,04 \mathrm{E}-03$ \\
\hline$I C R$ (adults) & --- & --- & --- & $2,19 \mathrm{E}-04$ & $6,05 \mathrm{E}-05$ & $7,13 \mathrm{E}-03$ & $2,64 \mathrm{E}-02$ & --- & $R I S K=3,38 \mathrm{E}-02$ \\
\hline
\end{tabular}

Table 3. Results from deterministic estimation of hazard quotients and carcinogenic risk of water from the Molochna river chemical contamination 
Reference doses were taken for chronic exposure, because continued pollution of the river by flushing pollutants from the territory is expected. According to the data from the above-mentioned work, emission of 1000 tons of fumes, 3000 tons of dust and 5 tons of ashes occurred. RfD and $S F$ values were taken accordingly ${ }^{11}$, and the $S F$ value for nickel was taking according to ${ }^{12}$.

As we can see, the table 3 calculation results indicate a significant threat to the health of the inhabitants of Troitske village, because they exceed the permissible value (RISK > 1,0E-03, $H I>1,0)$. Clearly, in this case, it is appropriate to conduct more complex probabilistic risk assessment, because the decision based on the results of the determined assessment require additional expenses for risk reduction.

\section{Tier 2. Probabilistic risk assessment}

As has been stated above, during probabilistic risk assessment (PRA), instead of point values of the intput variables, probability distributions are used which are inserted into the model for risk assessment and, using the Monte Carlo method, we determine the probabilistic distribution of risk. Probabilistic approaches have to cover all components of the assessment process, but, in practice, only the exposure component is usually used, at least for assessing the impact of pollutants on human health, i.e. $R f D$ and $S F$ values before obtaining additional data are recommended for use as point values ${ }^{13}$.

Therefore, to determine the probability of risk value (equations (1) and (3)), it is necessary to determine the distribution of the average daily dose of $A D D$ chemical substances which enter into a human body with drinkable water. This is done by substituting the equation (5) deterministic intput variables with probabilistic

11 P 2.1.10.1920-04 Guidance for risk assessment of the health of population at influence of chemical substances contaminating an environment Moscow 2004116 pp. (in Russian).

12 Cancer Potency Values OEHHA 2009 http://oehha.ca.gov/risk/pdf/TCDBcas061809. pdf.

13 EPA 540-R-02-002. Risk Assessment Guidance for Superfund: Process for Conducting Probabilistic Risk Assessment. Vol. III. Part A. http://www.epa.gov/superfund/RAGS3A/ index.htm. 
distributions determined with the help of the Monte Carlo method distribution of $A D D$. With the exception of chemical concentration $C w$, the remaining values are normal physiological parameters of the human body and, as such, can be used like surrogate data defined in another place. For example, according to ${ }^{14}$

$$
A D D=(C w \cdot I R W) / 1000,
$$

where $A D D$ is the daily dose of chemical substances per unit mass $\mathrm{mg} /(\mathrm{kg} \cdot$ day); $\mathrm{Cw}$ - the concentration of chemical in water, $\mathrm{mg} / \mathrm{l}$;

$I R W$ - amount of water per body weight, consumed per day, $\mathrm{ml} /(\mathrm{kg} \cdot$ day).

By processing more than 26,000 pieces of data about water consumed during the day, it was found that $I R W$ has the shape of lognormal distribution with parameters depending on the age of those who consume water. Making assumptions that distributions of data of concentrations of pollutants in water is truncated normal distribution (the concentrations cannot be negative) from equation (6) can determine the distribution of $A D D$, and, from the equations (1) and (3) determine distribution of RISK and HI. The initial data for the lognormal distribution of IRW is shown in table 4, and normal distributions of $C w$ are shown in table 1 (for each substance, the mean concentration and its standard deviation are listed).

A risk assessment was carried out for people from different age groups: kids - 1-6 years, teens - 7-14 years and adults - 15-75 and older. Modelling was performed using an Excel $^{\circ}$ spreadsheet adding Crystal Ball over them. Graphically, the distribution of risk is reflected in Fig. 5. Vertical lines depict deterministic risk assessment values.

Fig. 5 shows that values of deterministic risk assessment, excluding the value for kids (table. 3), exceed their most likely values and are too conservative. However, the most likely value still exceeds acceptable risk value, and that means threat to the majority of population. It makes sense to move on to the third tier of assessment, especially with the presence of a sufficient number of statistics.

14 Guidance for use of probabilistic analysis in human health risk assessments. Portland, Oreg. DEQ, 1998158 pp. 


\begin{tabular}{|l|l|l|l|l|}
\hline Age group, years & $\mu$ & $\sigma$ & lower limit & upper limit \\
\hline $1-3$ & 3,49 & 0,75 & 5,81 & 186,49 \\
\hline $4-6$ & 3,33 & 0,68 & 5,80 & 135,78 \\
\hline $7-10$ & 2,97 & 0,68 & 4,04 & 94,71 \\
\hline $11-14$ & 2,66 & 0,71 & 2,77 & 74,24 \\
\hline $15-19$ & 2,43 & 0,74 & 2,02 & 63,93 \\
\hline $20-44$ & 2,61 & 0,68 & 2,77 & 67,11 \\
\hline $45-64$ & 2,92 & 0,52 & 5,45 & 62,71 \\
\hline $65-74$ & 2,92 & 0,49 & 5,92 & 58,47 \\
\hline $75+$ & 2,88 & 0,50 & 5,61 & 56,84 \\
\hline
\end{tabular}

$\mu$ - the average value of the natural logarithm $I R W$;

$\sigma$ - the standard deviation of the natural logarithm IRW

Table 4. The parameters for the lognormal distribution of drinking water, consumed per day $(I R W), \mathrm{ml} /(\mathrm{kg} \cdot$ day $)$

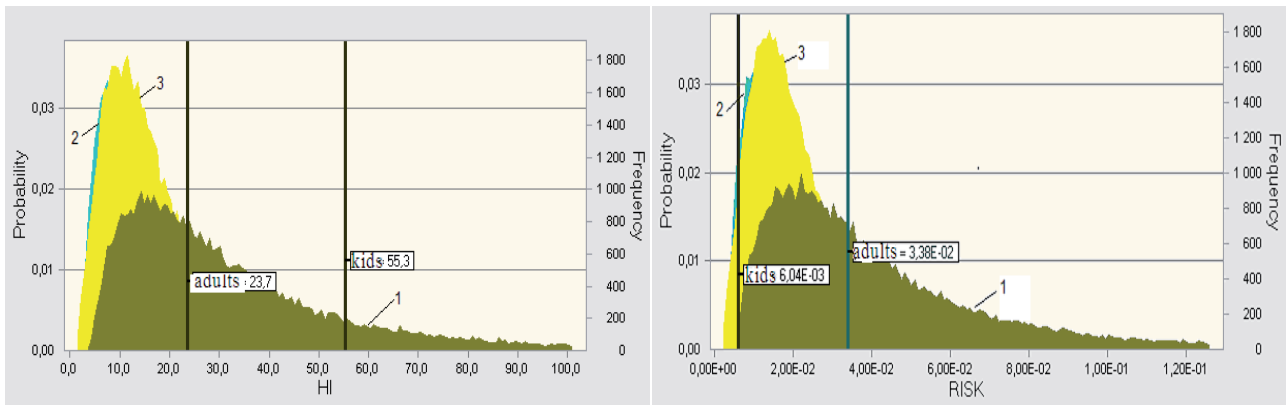

Source: own development.

Figure 5. Probabilistic distributions of non-carcinogenic (left) and carcinogenic (right) risk in the use of drinking water: 1 - kids; 2 - teens; 3 - adults

\section{Tier 3. Advanced probabilistic risk assessment}

On the $2^{\text {nd }}$ tier, probabilistic risk assessment is carried out using the onedimensional Monte Carlo method, which means that only the impact of variability of input parameters was determined. The initial parameters were concentrations of pollutants in water and normalised per unit weight of human body amount of daily consumed water. It was assumed that the distribution of contaminant concentrations in water is determined solely variably, for example, due to seasonal rainfall, etc. 
Now, we assume that distribution concentration is determined by ignorance too, for example, through different measure conditions. The normalised per unit weight amount of daily consumed water, of course, is determined by the variability of the individual characteristics of the human body. In this case, the separate impact of variability and ignorance is determined using the two-dimensional Monte Carlo method.

A risk assessment was carried out for the same categories of people as in tier 2 . Modelling was performed using an Excel' spreadsheet adding Crystal Ball' over them. For probabilistic risk assessment that is conducted using the two-dimensional Monte Carlo method, it is convenient to use trend charts. The following charts for the assessment of carcinogenic risk and hazard index for the assessment of noncarcinogenic risk for all categories of the population are depicted in Fig. 6 after 10 000 iterations of uncertainty and 100 iterations of ignorance.

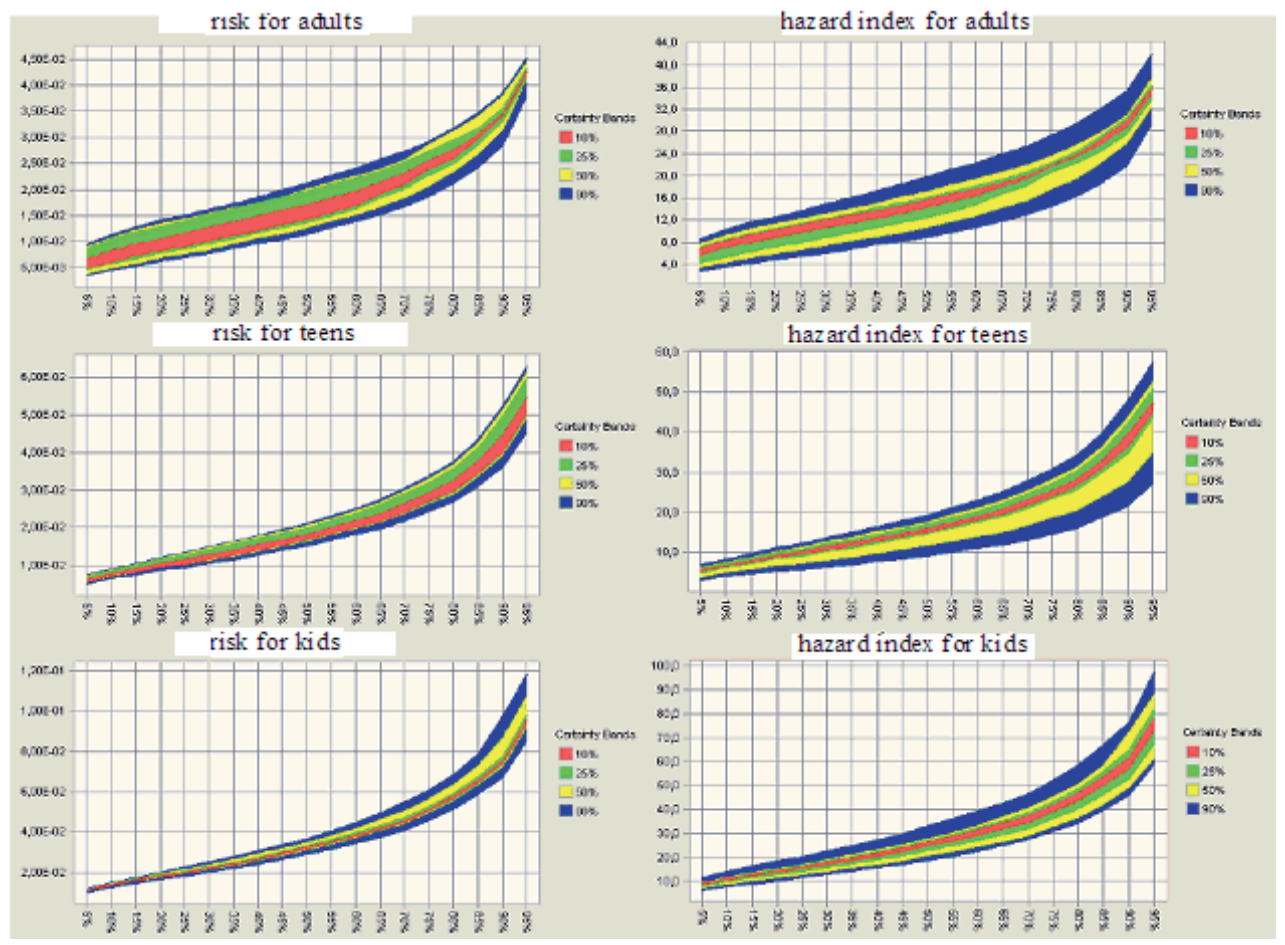

Source: own development.

Figure 6. Trend charts of the probabilistic cancer risk assessment (left) and hazardous index of Non-carcinogenic risk (right) for all population groups which consume contaminated water 
On trend charts, areas of equal probability for achieving certain values of carcinogenic and non-carcinogenic risk are displayed (vertical axis) for a certain percentage of the population (horizontal axis). For example, for $50 \%$ of adults, the value of carcinogenic risk with a probability of $90 \%$ will be $(1,2-2,2) \cdot 10^{-2}$ and for $90 \%$ of the same population with the same probability respectively $(2,8-3,8) \cdot 10^{-2}$. With a probability of $10 \%$, these values will be as follows $(1,7-2,1) \cdot 10^{-2}$ and $(3,4-$ $3,5) \cdot 10^{-2}$.

\section{Summary}

1) Assessment and further analysis of environmental risk provides much more useful information for making environmental decisions compared to the methodology of threshold concentrations.

2) Risk assessment should be carried out in stages (tiers), from the simple (deterministic)tomorecomplex(usingone-dimensionalorlatertwo-dimensional Monte Carlo method), when there are the following requirements:

- the need to set priorities among the areas of contaminants, pollutant transfer routes and other factors;

- resources to perform environmental protection measures are limited;

- significant consequences as a result of wrong decisions;

- available information is insufficient for making reliable decisions.

3) As for the issues regarding consumption of contaminated water, it is clear that this water is not suitable like potable water.

\section{Bibliography}

Cancer Potency Values OEHHA 2009 http://oehha.ca.gov/risk/pdf/TCDBcas061809.pdf. Cullen A. C. Probabilistic techniques in exposure assessment. A handbook for dealing with variability and uncertainty in models and inputs / Alison C. Cullen, H. Christopher Frey - New York, NY: Plenum, 1999. - 335 p.

EPA 540-R-02-002. Risk Assessment Guidance for Superfund: Process for Conducting Probabilistic Risk Assessment. Vol. III. Part A. Washington, DC, 2001. - http://www. epa.gov/superfund/RAGS3A/index.htm. 
EPA/100/B-04/001. An Examination of EPA Risk Assessment Principles And Practices. Washington, DC: EPA, 2004. - 193 p.

EPA/540/1-89/002. Risk Assessment Guidance for Superfund: Human Health Evaluation Manual. Part A. Interim Final. Washington, DC, 1989. - http://www.epa.gov/ower/ riskassessment/ ragsa/index.htm.

EPA/600/R-09/052F. Exposure factors handbook. - Washington, DC, 2011. - http://www. epa.gov/ncea/efh.

EPA/630/R-97/001. Guiding Principles for Monte Carlo Analysis. - Washington, DC, 1997.

- http://www.epa.gov/raf/publications/pdfs/montecar.pdf

Guidance for use of probabilistic analysis in human health risk assessments. Portland, Oreg. DEQ, 1998158 pp.

Human and Ecological Risk Assessment: Theory and Practice Dennis J. Paustenbach (Ed.). - New York, NY: Wiley, 2002. - 1586 p.

J. Solarz Chemical contamination - typology of threats. NDU Scientific Quarterly no 4(93) 2013 p. 207-223.

S.I. Azarov, V.I. Palamarchuk, V.L. Sydorenko. Risk assessment for population, which uses drinkable water after accident on an ammunition depot. Transactions of Kremenchuk Mykhailo Ostrohradskyi national university No 5 (64) pt.1 2010 p. 141-144 (in Ukrainian)

WHO human health risk assessment toolkit: chemical hazards. - Geneva: WHO Press, 2010. - 105 p. 